\title{
Erratum to: Meiotic recombination analysis in female ducks (Anas platyrhynchos)
}

L. del Priore ${ }^{1}$ M. I. Pigozzi ${ }^{1}$ (I)

Published online: 14 September 2016

(C) Springer International Publishing Switzerland 2016

\section{Erratum to: Genetica (2016) 144:307-312 \\ DOI 10.1007/s10709-016-9899-9}

Unfortunately, the order of authors was published incorrectly in the original publication. The correct order is given in this erratum.

The online version of the original article can be found under doi:10.1007/s10709-016-9899-9.

\footnotetext{
M. I. Pigozzi

mpigozzi@fmed.uba.ar

1 INBIOMED-Instituto de Investigaciones Biomédicas, Universidad de Buenos Aires-CONICET, Facultad de Medicina (UBA), Paraguay 2155, Piso 10,

C1121ABG Buenos Aires, Argentina
} 